\title{
In-situ crystallisation study of phase-change material using transmission electron microscopy
}

\author{
M. Kaiser ${ }^{1}$, L. van Pieterson $^{2}$ \\ ${ }^{1}$ Philips Centre for Industrial Technology, Professor Holstlaan 4, 5656 AA Eindhoven, The Netherlands \\ ${ }^{2}$ Philips Research Laboratories, Professor Holstlaan 4, 5656 AA Eindhoven, The Netherlands
}

In the rewritable versions of CD and DVD, storage of information is based on writing amorphous marks in a crystalline phase-change material. Data can be overwritten by inducing recrystallisation of the marks $[1,2]$. Understanding of the crystallisation properties of a phase-change material is therefore an important aspect in the optimization of phase-change materials.

To study the (re)crystallisation behaviour of phase-change materials for rewritable optical disc applications, TEM analysis is a frequently used and dedicated method [1-3]. Most actual information is obtained of laserrecrystallised marks. However, TEM-analysis of laser-induced recrystallised amorphous marks gives no dynamic information on the crystallisation process. Therefore we used in-situ TEM analysis to investigate the crystallisation mechanism of a new phase-change material $\left(\mathrm{Ga}_{15} \mathrm{Sb}_{85}\right)$ [4] by using either a heating holder or the electron beam itself to crystallise the material.

Conventional CD-RW discs are used for the studies. These discs consist of a $\mathrm{ZnS}: \mathrm{SiO}_{2}$ (80:20)/ $\mathrm{Ga}_{15} \mathrm{Sb}_{85} 14 \mathrm{~nm} / \mathrm{ZnS}: \mathrm{SiO}_{2}(80: 20) / \mathrm{Si}_{3} \mathrm{~N}_{4} / \mathrm{Ag} / \mathrm{Si}_{3} \mathrm{~N}_{4}$ layered stack on a polycarbonate (PC) substrate. The phase-change layer is amorphous after deposition and is laser-crystallised. Amorphous data marks are 'written' in the initialised material using a home-built CD recorder. For TEM imaging the following preparation procedure is followed: the $\mathrm{PC}$ substrate is dissolved in chloroform, the $\mathrm{Si}_{3} \mathrm{~N}_{4}$ layer is etched in $\mathrm{HF} / \mathrm{NH}_{4} \mathrm{~F}$ 1:7 and the Ag layer is etched in $\mathrm{Na}_{2} \mathrm{~S}_{2} \mathrm{O}_{3}$ solution $\left(1.26 .10^{-3} \mathrm{M}\right)$. The resulting samples - containing the phase-change layer sandwiched between two dielectric layers - are deposited onto TEM-Cu grids. TEM studies are performed using a Philips CM12ST TEM, operated at $120 \mathrm{kV}$. Heating is either performed in-situ in the TEM in a standard TEM heating holder (Philips) up to temperatures of $220^{\circ} \mathrm{C}$, or by using the electron beam operated at different intensity settings. For comparison, the appearance of laser-recrystallised marks is studied as well.

Fig. 1 shows a TEM picture of laser-crystallised phase-change material with several amorphous marks. The structure of the crystalline material was determined with electron diffraction as a rhombohedral $\mathrm{Sb}$ structure [5] with a strong in-plane $<110>$ texture (see left part Fig. 1). Marks $\mathrm{x}$ and y are partly recrystallised by the laser of the CD-player, caused by growth of crystals originally decorating the edges of the marks. Amorphous marks that are completely crystallised with the laser beam contain only large crystals with the same rhombohedral $\mathrm{Sb}$ structure as the already crystalline phase-change material. In order to obtain more insight in the crystallisation mechanism in-situ measurements in the TEM were performed. Fig. 2 shows TEM pictures of a sample with a single track of regularly spaced amorphous marks in a laser-crystallised phase-change material. Crystallisation was induced by heating in the TEM and starts with the formation of many nuclei within the amorphous mark, see Fig. 2(b). Finally, small crystallites with the rhombohedral $\mathrm{Sb}$ structure cover the formerly amorphous area (Fig. 2(c)). In addition to this nucleationdominated recrystallisation process, erasure of the marks by growth from the edges could be realised by changing the temperature budget.

In another attempt to study in-situ recrystallisation we used the electron beam to induce crystallisation of the phase-change material (without using the heating holder). Several movies were recorded in order to analyse this crystallisation behaviour of $\mathrm{Ga}_{15} \mathrm{Sb}_{85}$. Fig. 3 shows the crystallisation of an amorphous mark in a crystalline phase-change layer step-wise. Using special settings of the electron beam, the process of crystallisation proceeded slowly at a typical rate of $10-28 \mathrm{~nm} / \mathrm{s}$. The growth of large crystals starting from the crystalline edges was observed. Electron diffraction of the recrystallised area shows a structure with lattice parameters of about 3 or 4 times the Sb unit cell. Most likely, a superstructure has been formed. For the phase- 
change materials that are currently applied in rewritable recording, like $\mathrm{Ge}_{2} \mathrm{Sb}_{2} \mathrm{Te}_{5}$ [6] and doped (eutectic) $\mathrm{Sb}-\mathrm{Te}$, super structures have been reported, but only after heating considerable time.

In conclusion, the crystallisation of amorphous marks in a crystalline phase-change layer has been studied insitu in the TEM. Crystallisation could be induced either by conventional heating or by the electron beam itself. However, the recrystallisation mechanisms and the resulting recrystallised materials are markedly different from each other and from the laser beam recrystallised material, suggesting a strong dependence on thermal budget. Therefore, caution should be taken in interpreting in-situ (re)crystallisation TEM data of phase-change layers.

[1]: H.J. Borg, J. Magn. Mater. 193, 519 (1999),

[2]: G.F. Zhou, Mater. Sci, Eng., A 304, 73 (2001)

[3]: O. Bostanjoglo and G. Schotzhauer,

Phys. Stat. Sol. (a) 68, 555 (1981)

[4]: L. van Pieterson, M. van Schijndel, M. Kaiser, J.C.N. Rijpers, to be published

[5]: Swanson, Fuyat, Nat. Bur. Stand. (U.S.), Circ 539, 3, 14 (1954)

[6]: B.J. Kooi and J.Th.M. de Hosson,

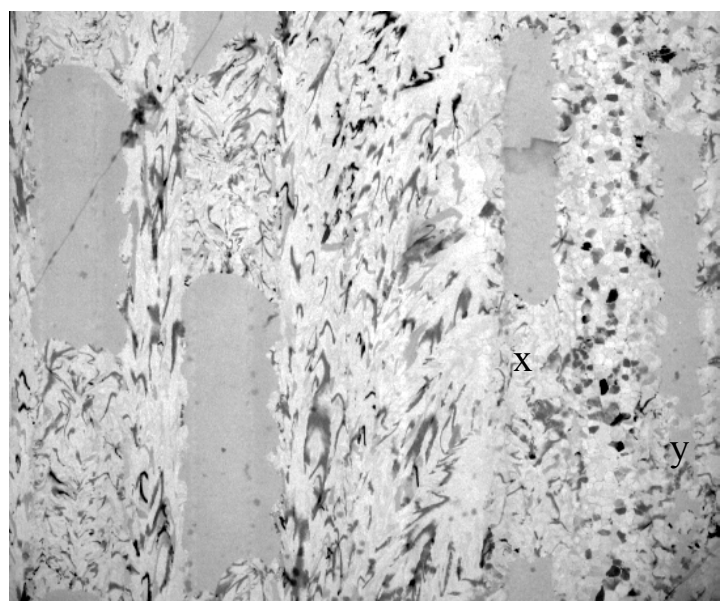

J. Appl. Phys. 92, 3584 (2002)

Fig. 1: original amorphous marks (left) and marks ( $x$ and $y$ ) partly recrystallized by laser beam, in crystalline background.
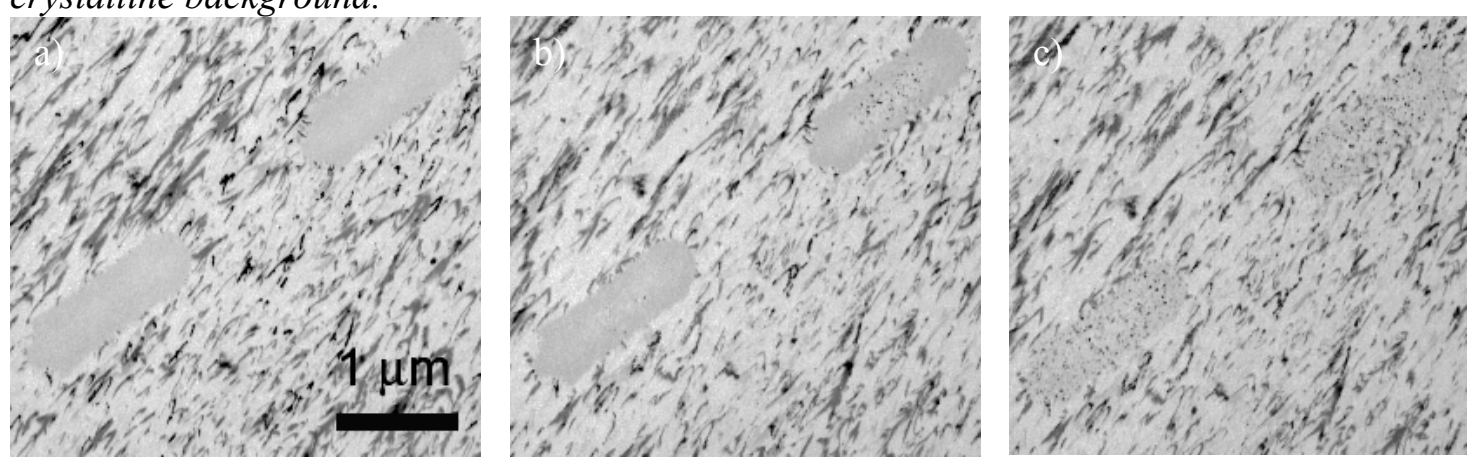

Fig. 2: separated data marks a) before heating in the TEM heating holder, b) after 20 minutes at $220{ }^{\circ} \mathrm{C}$, c) after 55 minutes at $220{ }^{\circ} \mathrm{C}$.
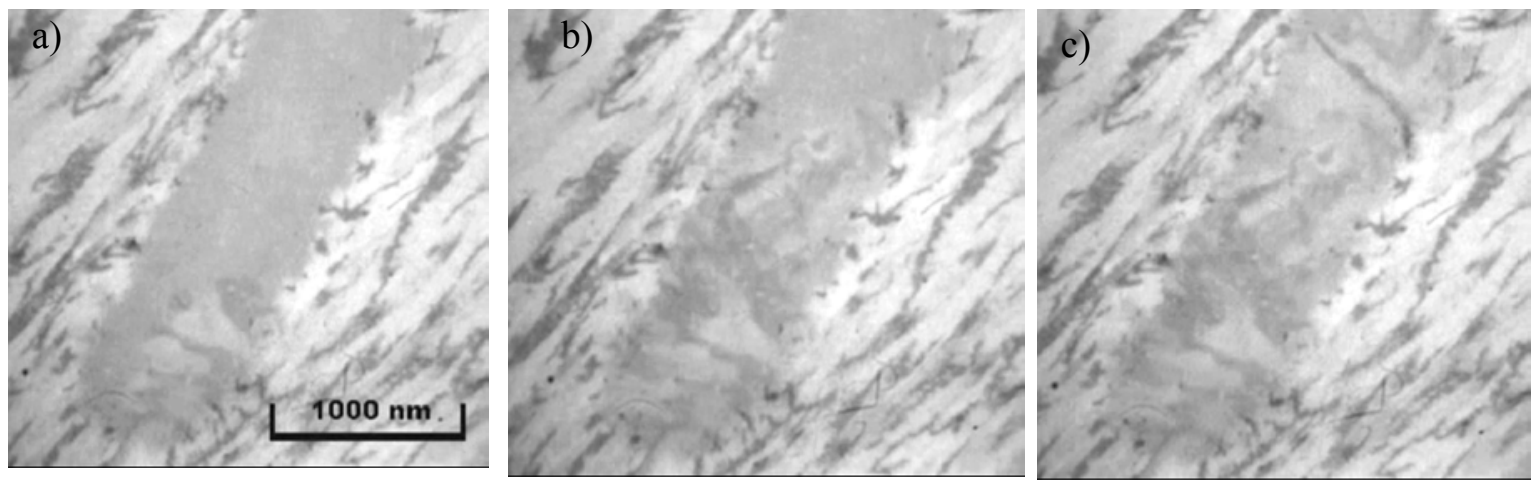

Fig. 3: data mark after a) 60“, b) 195” and c) crystallisation using the electron beam has completed. 